\title{
IDEAÇÃO E TENTATIVA DE SUICÍDIO EM ESTUDANTES DE PSICOLOGIA: UMA DOR QUE TEM MORADA NA UNIVERSIDADE
}

\author{
A.K.S. AZEVEDO, M.V.M. SILVA*, A.P.S. LIMA \\ Universidade Federal do Rio Grande de Norte \\ vanessamorais-cr@hotmail.com* \\ Artigo submetido em 10/08/2017 e aceito em 16/10/2019 \\ DOI: $10.15628 /$ holos.2019.6203
}

\section{RESUMO}

A Organização Mundial da Saúde estima que mais de 800 mil pessoas morrem devido ao suicídio todos os anos, entretanto, apesar desse expressivo índice, ainda é um assunto tabu e carente de discussão em diferentes esferas, como: a escola, a mídia e, fundamentalmente, nos currículos e formação de profissionais de saúde, incluindo a Psicologia. Este trabalho é fruto de uma pesquisa qualitativa que entrevistou estudantes do curso de psicologia da FACISA-UFRN e tem como objetivo compreender aspectos relacionados a ideações e tentativas de suicídio, presentes na história de vida desses estudantes. Em nossa pesquisa foram utilizados questionários semiestruturados, os quais foram analisados em dois momentos: as perguntas fechadas foram submetidas a tratamento estatístico simples e as perguntas abertas foram analisadas a partir do discurso dos participantes à luz da fenomenologia existencial, embasando-nos para nossa análise em autores dessa perspectiva que já trabalham o tema do suicídio. Participaram do estudo 63 estudantes do 1 으 e 3 으 períodos de Psicologia. Pudemos constatar a tentativa de suicídio presente em $11,50 \%$, e no que se refere a ideação suicida, emerge um quantitativo de $47,22 \%$ da amostra. Percebemos que o suicídio aparece como sofrimento, desespero, fuga, angústia e, sobretudo, como escolha existencial. A possibilidade de suicidar-se surge de maneira multifacetada, estando correlacionada com várias outras questões, inclusive com o fazer profissional dos estudantes e futuros psicólogos. Existe um sofrimento evidente relacionado a temática do suicídio, sendo necessário pensar em ações que contribuam para abordar tal fenômeno entre os universitários, e também para além disso, pensar a necessidade de termos mais estudos na área, propiciando compreensões sobre o fenômeno do suicídio.

PALAVRAS-CHAVE: Suicídio, Estudantes de Psicologia, Fenomenologia existencial, Sofrimento.

\section{SUICIDE IDEATION AND ATTEMPT IN STUDENTS OF PSYCHOLOGY: A PAIN THAT HAS LIFE IN THE UNIVERSITY}

\begin{abstract}
The World Health Organization estimates that more than 800,000 people die from suicide every year. However, despite this significant rate, it is still a taboo subject and needs discussion in different spheres, such as: school, the media and, fundamentally, curricula and training of health professionals, including psychology. This work is the result of a qualitative research that interviewed students of the psychology course at FACISA-UFRN and aims to understand aspects related to ideations and suicide attempts, present in the students' life history. In our research we used semi-structured questionnaires, which were analyzed in two moments: closed questions were submitted to simple statistical treatment and open questions were analyzed from the participants' discourse in the light of existential phenomenology, grounding us
\end{abstract}

for our analysis in authors. From this perspective, the subject of suicide is already working. Sixty-three students from the 1st and 3rd periods of psychology participated in the study. We could observe the suicide attempt present in $11.50 \%$, and with regard to suicidal ideation, a quantity of $47.22 \%$ of the sample emerged. We realize that suicide appears as suffering, despair, escape, anguish and, above all, as existential choice. The possibility of committing suicide arises in a multifaceted manner, and is correlated with several other issues, including the professional doing of students and future psychologists. There is evident suffering related to the suicide theme, being necessary to think about actions that contribute to address this phenomenon among the university students, and also, to think about the need for further studies in the area, providing insights on the phenomenon of suicide.

KEYWORDS: Suicide, Psychology students, Existential Phenomenology, Suffering. 


\section{INTRODUÇÃO}

A tentativa de suicídio, mais do que uma questão filosófica, religiosa ou social é um grave problema de saúde pública. A Organização Mundial da Saúde (2006) estima que mais de 800 mil pessoas morrem devido ao suicídio todos os anos, sendo a segunda principal causa de morte entre indivíduos com idade entre 15 e 29 anos. Ademais, estima-se que, a cada 40 segundos, uma pessoa comete suicídio.

O suicídio apesar de seus altos índices ainda é um fenômeno subnotificado e pouco discutido, além de ser um assunto tabu em nossa sociedade. Entretanto, apesar de percebermos certa interdição na discussão deste tema, atualmente, a partir da veiculação de seriados ${ }^{1}$ e filmes que tematizaram a questão do suicídio, o seu debate tem sido convocado. Todavia, entendemos que sua discussão deve ser expandida para os mais diferentes espaços da sociedade, quais sejam: a escola, a mídia e, fundamentalmente, nos currículos e formação de profissionais de saúde, incluindo, a Psicologia.

O presente trabalho permite conhecer as dificuldades enfrentadas pelos alunos do curso de Psicologia, os quais estudam em um campus da área da saúde no interior do Nordeste brasileiro, propiciando a reflexão de uma avaliação da saúde mental destes e fomentando a construção de ações e intervenções que proporcionem a melhoria do bem-estar dos mesmos, mediante a compreensão de aspectos relacionados a ideações e tentativas de suicídio presentes na história de vida desses estudantes.

De acordo com Dutra (2012), no Brasil não são atípicas as notícias sobre suicídio entre os estudantes universitários. Em meio ao estresse diário de uma vida acadêmica, muitas vezes longe de casa e tendo que assumir responsabilidades as quais antes não possuíam, os estudantes sentemse sobrecarregados e em alguns momentos tendem a encarar a ideação de suicídio como uma possibilidade.

Sendo assim, ressaltamos a importância de estudar o fenômeno do suicídio entre os estudantes de Psicologia, tendo em vista a natureza da formação acadêmica do curso, que constantemente demanda do aluno uma reflexão sobre a realidade, corroborando para acentuar certos aspectos emocionais e pessoais da sua existência.

Isso posto, em seguida veremos como o tema é abordado pela literatura, fazendo-se necessário explorar o assunto a partir de autores que trabalham a temática, e assim compreendermos melhor sobre o fenômeno do suicídio.

\section{REVISÃO BIBLIOGRÁFICA}

Segundo Lovisi, Santos, Legay, Abelha e Valencia (2009) o fenômeno do suicídio se apresenta como uma questão importante de saúde pública em todo o mundo. Em estimativa, a OMS (2006)

\footnotetext{
${ }^{1}$ Produções televisivas como: "13 Reasons Why" e o desafio virtual "Baleia Azul”.
} 
apresenta que mais de 1,5 milhões de pessoas vão cometer suicídio até 2020. O Brasil aparece entre os 10 países com maior índice de suicídio.

Ainda de acordo com Lovisi et al. (2009) as taxas de suicídio ao redor do mundo se diferenciam a partir de aspectos culturais, regionais e sociodemográficos, como também a forma que estas mortes são registradas. No Brasil, alguns pesquisadores têm mostrado que a subnotificação e a baixa qualidade das informações contidas nos certificados de óbito nos coloca em alerta, pois esses fatores podem levar à subestimar o quantitativo de mortes por suicídio nas taxas de mortalidade que são relatadas.

Botega (2014) diz que, além de sub-registro e de subnotificação, há outro problema como os suicídios disfarçados que ganham outra nomenclatura de causa de morte, que é o caso, por exemplo, dos acidente de carro, afogamento, envenenamento acidental e maioria das informações com denominação de "morte de causa indeterminada".

Esses autores nos trazem uma característica intrínseca quando estudamos o suicídio, que é a dificuldade de coletar informações precisas com relação ao número de casos, seja por subnotificação, seja má alimentação dos dados de mortalidade, ou ainda por uma questão de atenuação do fenômeno se utilizando de disfarces por um fator cultural e social que estigmatizam o ato suicida.

Cassorla (1991, p. 30), menciona que: "o suicídio é uma agressão deliberada que o indivíduo exerce contra si mesmo com o sentido de pôr um fim à sua vida."

Kovács (2013) nos lembra que a morte é um tabu em nossa sociedade e em se tratando de suicídio é um tema bastante complexo. Logo, para tal temática só cabe intervenções pertinentes e profundas reflexões, para que um erro de uma explicitação simplória não promova intenso sofrimento.

Kovács (2013) diz que é de extrema importância discutir o assunto entre os jovens, levantando os dados e tentando compreender a realidade do fenômeno, para que eles pensem entre si que intervenções possam ser executadas e quais questões consideram importantes abordar sobre a temática e Cassorla (2004) nos mostra que os jovens podem cometer suicídio como meio de encontrar uma vida nova, adrenalina, um pedido de ajuda ou ainda para tornar público que algumas coisas não estão indo muito bem em suas vidas.

Hoje sabemos que o suicídio é a ponta do iceberg de uma série de comportamentos e fantasias. Ao contrário das definições comuns (incluindo a de Durkheim), raramente o indivíduo possui a lucidez que se supõe, para saber que o seu ato o levará à morte. Mais ainda, os seres humanos ignoram o que é a morte e criam fantasias sobre ela, como uma nova vida em 'outro lugar', por exemplo. (Cassorla, 1998, p. 28).

Para Dutra (2011) não é viável se propor a dar respostas fechadas e únicas sobre o suicídio, pois entende-se, entre os estudiosos da temática, que o suicídio é um fenômeno multideterminado só podendo ser compreendido a partir da biografia de quem o vive. Esta mesma autora, esclarece que os possíveis motivos que podem levar alguém a cometer suicídio são construídos ao longo da história de vida de cada um e são revelados nos sentidos e modos de ser que eles adotam para sua 
existência. Sendo assim um fenômeno que acontece independentemente da idade, classe social ou gênero. Para Dutra (2011), o suicídio tem um significado de sofrimento e desespero, algo mobilizador que promove uma abertura de questionamento sobre o sentido da vida.

De acordo com Azevedo e Dutra (2012) é possível pensar a tentativa de suicídio como uma escolha de não mais viver, como um des(amor) por si próprio, um abandono dos projetos e sonhos, deixando de amar seu ser.

Azevedo e Dutra (2012) completa que por mais que a tentativa de suicídio venha a ser interpretada como um ato extremo, ela também pode ser entendida como um modo de ser, uma forma de existir. Para tanto, compreender a história de vida do suicida pode nos levar a entender que escolher pela morte talvez seja uma tentativa de criar uma potência de existir, uma força de continuar vivendo, mesmo que nas lembranças do outro.

Para o suicida a morte aparece como possibilidade real e imediata de calar uma dor, silenciar um sofrimento, de pôr fim à falta de sentido que é continuar vivendo. Quando se pensa numa possível tentativa de suicídio, pensa-se em acabar com a angústia que dilacera seu viver, que promove um enorme vazio existencial e faz do nada lugar em si.

Estudantes da área de saúde são propensos a apresentar sintomas depressivos e ansiosos durante seu curso, que podem impactar o seu futuro profissional. A presença desses sintomas atrelados com outros fatores socioeconômicos, históricos e ambientais, pode levar o estudante ter dificuldades em seguir o curso, aumenta o risco de desenvolvimento de quadros de dependência química e risco de suicídio. A literatura mostra que os estudantes da área da saúde como medicina, enfermagem e farmácia, por exemplo, explicitam uma prevalência de sintomas depressivos e ideação suicida (Alves, 2014).

Em uma pesquisa realizada com 233 estudantes de Psicologia de uma universidade pública brasileira, com o objetivo de identificar a presença do pensamento suicida nesses estudantes, constatou a presença de 26 estudantes que tiveram ideação suicida, o que corresponde a $11 \%$ da amostra. A faixa etária era entre $18-22$ anos e $30 \%$ dos estudantes pesquisados que apresentaram ideação suicida estavam entre os primeiros períodos do curso. E dos estudantes que já tentaram o suicídio em algum momento de suas vidas, observou-se que mais da metade (55\%) estava mais uma vez apresentando pensamentos suicida. (Vieira \& Coutinho, 2008).

No estudo citado anteriormente, entre estudantes de Psicologia, o suicídio aparece com alguns sentidos, como: desesperança perante a vida, fuga, uma saída para problemas difíceis, uma doença, decorrente de um desequilíbrio, que causa medo e tristeza, um meio extremo para as adversidades, dentre outros.

Ainda sobre pesquisas desenvolvidas abordando a temática do suicídio em estudantes de Psicologia, Dutra (2012) desenvolveu estudo com 637 estudantes de Psicologia, em duas universidades (uma pública e uma privada) e duas faculdades, na cidade de Natal-RN. E em João Pessoa-PB, foram entrevistados 374 estudantes do curso de Psicologia da maior universidade pública deste estado. Os resultados preocupam, visto que, no RN, dos 637 alunos que responderam ao questionário de pesquisa, 52,45\% afirmaram que sentiam vontade de morrer; 48 dos estudantes 
pesquisados, ou seja, 7,5\% do total, haviam tentado se matar. Na Paraíba, os dados são ainda mais preocupantes, quando comparados aos encontrados no RN. Entre os 374 alunos que responderam ao questionário aplicado, 43 pessoas haviam tentado se matar, correspondendo a 11,49\% da população pesquisada. Tais resultados desvelam a necessidade da realização de outros estudos que contribuam com a reflexão do tema e dos aspectos psicossociais e existenciais favorecedores desse ato.

\section{METODOLOGIA}

O presente estudo configura-se como parte de uma análise de um projeto de pesquisa que tem como título "A IDEAÇÃO E TENTATIVA DE SUICÍDIO EM ESTUDANTES DA ÁREA DA SAÚDE EM SANTA CRUZ/RN". Em nossa pesquisa elencamos os dados do curso de Psicologia, este que compõe um quadro dentre outros cursos neste campus. Ressaltamos ainda que tal pesquisa foi submetida e aprovada pelo comitê de ética em pesquisa.

Como método utilizamos a pesquisa qualitativa, a qual valoriza as manifestações humanas e sociais. Segundo Roehe (2006) a pesquisa qualitativa vem resgatar a presença humana com toda sua fluidez, seja temporal, social, histórica e emocional.

Para a coleta de dados foi utilizado um questionário como instrumento, não identificado e autoaplicável, contendo perguntas fechadas e abertas sobre a temática de ideação e tentativa de suicídio. Antes da aplicação do mesmo, foi lido o Termo de Consentimento Livre Esclarecido (TCLE), tanto para esclarecer as possíveis dúvidas sobre a aplicação dos questionários, quanto para atestar a participação voluntária como colaborador da pesquisa. O local de realização foi na Faculdade de Ciências da Saúde do Trairi - FACISA, entre os meses de abril e maio de 2016, e participaram da amostra estudantes do 1 o e 3 o períodos do curso de Psicologia, totalizando 63 questionários respondidos. Vale ressaltar que no período da pesquisa essas eram as únicas turmas existentes, tendo em vista que o curso de Psicologia foi oferecido nesse campus somente a partir de 2015.

Os questionários foram analisados em dois momentos: as perguntas fechadas foram submetidas a tratamento estatístico, utilizando o uso de cálculo percentual simples, ao passo que as perguntas abertas foram analisadas fenomenologicamente, identificando a partir das respostas, temas que emergiram das falas produzidas pelos entrevistados. Tais temas foram analisados à luz da literatura utilizada neste trabalho e de teóricos da área da fenomenologia existencial. Assim, buscamos refletir por meio da perspectiva aqui mencionada, permitindo a compreensão do fenômeno da ideação e tentativa de suicídio em estudantes de psicologia, que fazem parte da área da saúde no campus da UFRN, localizado em Santa Cruz/RN.

\section{RESULTADOS E DISCUSSÕES}

De um total de 63 alunos do curso de Psicologia que responderam ao questionário, a análise nos mostra que, mais de $84 \%$ dos alunos consideram o curso de psicologia bom, entretanto, um 
índice de 29,90\% elenca que a maior dificuldade enfrentada é a sobrecarga de estudos, aliada ao estresse provocado pela natureza da formação acadêmica.

Isto posto e corroborando com Calais, Andrade e Lipp (2003), em um estudo sobre suicídio entre universitários, no qual investigaram o estresse em jovens, constaram que esse estresse ocorre geralmente frente a uma necessidade de adaptação exigida dos alunos em momentos de mudança, que é o caso dos estudantes do curso de psicologia do primeiro e terceiro período que acabaram de entrar em uma graduação.

Desse modo, cabe-nos destacar o preocupante dado de que $29,90 \%$ dos estudantes pesquisados já referirem sobrecarga e estresse relativos à sua formação acadêmica. Lembramos que os cursos de Psicologia, no Brasil, segundo a resolução no 597, de 13 de setembro de 2018, pelo Conselho Nacional de Saúde (CNS) (2018), prevê que os cursos de Psicologia devem ter, no mínimo, 4000 horas, a serem integralizadas em no mínimo 5 anos, em caráter presencial, o que denota uma intensa atividade no transcorrer do curso, exigindo dos alunos um disponibilidade integral, para além da densidade das discussões acerca da natureza humana, que caracterizam o objeto de estudo da Psicologia.

Para os estudantes de Psicologia que responderam à pesquisa, o suicídio é visto em sua grande maioria, como tentativa de livrar-se de um sofrimento muito grande, onde a pessoa não consegue enxergar outra saída. Um ato de desespero, o ápice da angústia.

Alguns enxergam o suicídio como a perda de significado da própria existência e também como uma escolha:

Estudante 51: "Suicídio é quando o sujeito não enxerga mais possibilidades na vida. Vendo apenas a morte como seu ponto de libertação."

Estudante 52: "Suicídio é uma escolha existencial. É o meio que encontramos para acabar com o sofrimento, é a angústia que corrói nossa existência."

As falas dos estudantes 51 e 52 denotam uma desesperança em continuar vivendo, não conseguindo encontrar outra possibilidade que não seja a de querer morrer, tomando como essa opção um meio genuíno que possa libertá-los da dor e do sofrimento presentificados no seu ser. Essa vivência dolorosa que se anuncia como ferrugem da alma, permite pensar, que a partir da fala dos entrevistados, o suicídio parece ser uma escolha libertária para uma existência assolada pelo vazio que se desvela por meio da angústia. Lembramos que, muito embora o suicídio parece ser motivado por um único aspecto, ele é um fenômeno multideterminado e que só pode ser compreendido a partir da história de vida de quem o vive, de questões existenciais, que desvelam a perda de sentido da vida e fez do seu ser-para-a-morte, a sua única possibilidade de enfrentamento da dor vivida.

Para outros, o suicídio é visto como um ato egoísta e impensado, sendo uma maneira equivocada de pensar os problemas:

Estudante 41: "Uma forma de morrer que pode ser evitada, pois para o suicida, a vida acabou, mas o sofrimento de familiares e amigos continua." 
Estudante 33: "Pecado. Desperdício. Forma equivocada de acabar com problemas pequenos."

Algo que não abordamos anteriormente é o fato de que o suicídio é visto também através de um viés moral, como podemos perceber na fala do estudante 33, que por meio de uma visão particular, difundida por suas vivências, moraliza o suicídio, vendo o ato como um atentado a figura do Deus cristão, algo que é peculiar tendo em vista a predominância da cultura cristã em que acredita-se que somente Deus pode dar e tirar a vida, isto influencia e atravessa nossa construção de valores e entendimento sobre o suicídio. Ainda existem aqueles que minimizam o sofrimento do outro quando passam a julgar o problema alheio como pequeno e irrelevante para a morte. Cattapan (2012) nos lembra que quando se fala sobre suicídio é preciso que se abandone uma abordagem moral calcada numa perspectiva patologizante e biopolítica para que se possa reconhecer a legitimidade da liberdade do sujeito de optar por viver ou morrer.

Reafirmando esse pensamento, Morais e Sousa (2011) em um estudo sobre as representações sociais do suicídio, mostra que o ato implica em um julgamento moral, depreciativo e estigmatizado, estando associado com ausência de fé em Deus e com a depressão ligada a religiosidade. Nesse mesmo sentido, as autoras salientam que o suicídio é um comportamento humano complexo que levanta o julgamento moral a partir da visão de quem fala sobre a temática.

Com relação aos que sentiram vontade de morrer $54,70 \%$ afirmaram esta possibilidade, e destes, $47,22 \%$ queriam se suicidar. Sobre as tentativas de suicídio soma-se $11,50 \%$ e dentre esse percentual, 6,67\% tentaram mais de duas vezes. Percebe-se que este dado é relevante, tendo em vista que num universo de 63 alunos, 1 em cada 10 tentaram tirar a sua própria vida.

Esses dados, em nossa perspectiva impressionam, pois, dizem muito de um sofrimento, esse que pode ser proveniente de diversas áreas da vida desses estudantes, por isso, os números se tornam relevantes, especialmente se pensarmos a partir da perspectiva deste sofrimento que está latente e que emerge de questões individuais, sociais, culturais, familiares, acadêmicas, amorosas, financeiras, entre outras que movem o existir humano.

Pensar e compreender o suicídio dentro da universidade vai para além das questões burocráticas e acadêmicas que tornam estressantes o dia a dia do estudante, é também permitir que as "coisas mesmas" que os perturbam, dentro e fora da academia, apareçam e nos permitam interpretar o sofrimento por trás de um grito silenciado, que precisa morrer para falar. Como dito por Sabino (1986), o suicídio é um ato de publicidade, pois comunica o sofrimento de alguém.

A literatura nos apresenta algumas distinções a respeito de sentir vontade de morrer, idealizar e tentar. Alguns autores afirmam que:

As ideias suicidas, geralmente, estão associadas aos riscos de tentativas. Afirmam que $60 \%$ das pessoas que se matam possuem uma ideação suicida prévia, correspondendo, assim, ao principal fator de risco, finalizar tal ação. Com isso, fica clara a relação entre pensamento e ato no que tange a esses comportamentos, embora essa relação não seja defendida com unanimidade pela literatura especializada. (Silva et al., 2006, p. 1838). 
Ainda corroborando com essas questões sobre a diferença entre a vontade de morrer, idealizar e tentar, Dutra (2012) nos fala que de acordo com o SPRC (Suicide Prevention Resource Center) o suicídio é descrito como um final 'continuum', que inicia com a ideação, depois o planejamento e preparação e termina com a tentativa completa do suicídio.

Aqueles que disseram ter alguma dificuldade psicológica somou-se $23 \%$, referiram com maior frequência à depressão, seguida da ansiedade, portanto, de acordo com Dutra (2012) é importante considerar que tais distúrbios psíquicos podem ser fatores de risco para o suicídio. Esse aspecto aparece também no manual dirigido aos profissionais da saúde e da atenção básica sobre a prevenção do suicídio (Ministério da Saúde, 2009), quando menciona alguns fatores de risco, dentre os quais a depressão e os transtornos de ansiedade surgem entre eles.

É importante frisar que não necessariamente ter depressão ou ansiedade são condições que levem alguém a cometer suicídio, pois, no senso comum esses aspectos são levados em consideração como um fator determinante, porém não existe uma correlação direta para tal fenômeno. É bem verdade que não podemos eliminar dimensões psicossociais, entretanto, precisamos entendê-las como motivos e não como causas específicas.

Embora as dificuldades vivenciadas emocionalmente apareçam, 96,40\% notificaram que não fazem uso de medicação psicotrópica. Porém, mesmo não tendo um índice relevante do uso de medicamentos em nossa pesquisa, sabemos que o uso de psicotrópicos vem crescendo indiscriminadamente na sociedade nos dias atuais, como nos diz Dimenstein, Santos, Brito, Severo e Morais (2005).

Sobre a temática da ideação e tentativa de suicídio, 77,2\% afirmaram que pensar sobre tal assunto causa algum tipo de influência em sua vida, ao passo que $80 \%$ dos estudantes dizem que é mobilizador pensar na possibilidade de atender um paciente com queixa de suicídio, sentindo-se bem reflexivos ao pensar sobre isso, sejam elas reflexões positivas no sentido de poder estudar mais sobre a temática da ideação e tentativa de suicídio e o desejo de poder ajudar o outro, como também, proporcionando uma maior reflexão sobre sua própria finitude, sejam elas como uma visão negativa de não saber como lidar com a morte o que entre outros atributos gera sofrimento, receio e medo.

Esses dados são compreensivos, pois como o suicídio é considerado um tabu em nossa sociedade, falar sobre, se torna uma quebra de paradigmas, ainda mais com os alunos da área da saúde que são educados para salvar vidas e acabam vendo o suicídio como uma realidade cruel, para aqueles que poderiam viver e porventura escolher outra forma de lidar com o sofrimento que não fosse a morte.

É de extrema importância que essa temática seja estudada pelos estudantes de Psicologia, já que entrarão em contato com as esferas existências dos sujeitos e dessa forma precisam compreender que a morte também pode ser uma escolha para a aqueles que sofrem. Sobre isso:

Observa-se que a inserção do tema da morte na formação do psicólogo é importante porque, como profissional da área de saúde, ao lado de médicos e enfermeiros, a morte passou a fazer parte de seu cotidiano profissional. Nas escolas, há a necessidade de abordar o tema da morte, sendo exigida 
essa preparação do psicólogo escolar. No âmbito familiar, a perda de uma pessoa significativa ou de um animal de estimação demanda cuidados, especialmente com crianças. No contexto organizacional, o psicólogo vê-se frente à morte nos acidentes de trabalho e nas tentativas de suicídio, situações que necessitam de intervenção psicológica. (Junqueira \& Kovács, 2008, p. 508).

Apesar de se sentirem afetados negativamente, um número de $70,80 \%$ mencionou que o melhor encaminhamento a ser dado para esses casos é o psicológico, esse é um número bem expressivo que aparece, tendo em vista que entrevistamos estudantes de Psicologia que já reconhecem o lugar instituído de valor da psicoterapia. Outro fator mencionado pelos alunos que poderia determinar a causa de um suicídio seriam as escolhas existenciais, o que aparece como uma porcentagem de 50,60\%. A nossa existência é permeada por direções, escolhas e caminhos, fatores esses que podem estar envolvidos na escolha por não mais viver. Sobre isso, Dutra (2000) reflete:

A deficiência nesse processo de experienciação vai fazer com que as experiências mais autênticas não sejam vivenciadas. Tal modo inautêntico de viver acarretará escolhas existenciais inadequadas, porque incompatíveis com o seu ser verdadeiro, levando a pessoa a uma existência marcada pelo fracasso, pela baixa autoestima, irrealização e infelicidade, gerando uma total incapacidade de amar e ser amado. Dá-se, então, o vazio existencial e a falta de sentido para a vida, que podem levar o jovem a, numa postura fatal, querer sair do vazio e tentar preencher esse vácuo em que se encontra, ainda que seja em direção a um desconhecido que lhe resgatará do sofrimento, ainda que seja ceifando a sua vida através de um ato de extrema violência, como o são o suicídio e a tentativa de suicídio. (pp. 99-100).

Acerca dos sinais possíveis sobre um ato suicida, 40,90\% afirmaram que comportamentos como tristeza, depressão, alteração comportamental, falar em morrer e comportamentos agressivos e hostis indicam sobre um possível ato de suicídio. Corroborando para tal dado, Rocha, Boris e Moreira (2012) afirmam que não somente o ato em si, mas também pequenas atitudes e comportamos expressam um sofrimento latente e indicam que as coisas não andam bem, muito embora, isso acabe passando despercebido no dia a dia. Contudo, é importante ficar atento as simples posturas, podendo nos ser útil essa percepção, para podermos compreender a angústia e a vontade de não mais viver.

São inúmeros os sinais que podem indicar um ato suicida, destacando que $93,66 \%$ de nossos entrevistados acreditam que este é um gesto que pode ser prevenido. Aparecem na fala dos estudantes intervenções como: abordar cada vez mais o tema, ficar atento aos sinais das pessoas mais próximas, buscar um acompanhamento psicológico adequado e apoio familiar, proporcionar uma escuta efetiva, mediar um acolhimento empático e lançar luz sobre outros caminhos para uma escolha que não seja matar-se.

Em se tratando da avaliação dos alunos enquanto a formação, 89,70\% avaliam de maneira afirmativa que a mesma dispõe de um preparo para lidar com o paciente suicida. Entretanto não é em toda a graduação de psicologia e cursos da área da saúde que essa preparação é considerada efetiva pelos os alunos. Junqueira e Kovács (2008) ao realizarem pesquisa com 23 alunos do curso de psicologia de uma universidade do norte do Brasil, verificaram que, segundo os alunos, eles não se sentem preparados para lidarem com a morte e que o tema é abordado superficialmente durante a graduação. As autoras destacam que ainda há pouco espaço na formação do psicólogo para que 
se possa refletir sobre a morte, embora observa-se algumas iniciativas pontuais na graduação, pósgraduação e extensão.

$\mathrm{Na}$ atualidade o tema da morte vem sendo demandado significativamente, tendo em vista o alto índice de adoecimento, desastres e os casos de morte violenta propagada pela mídia. E como fica o psicólogo perante a questão da morte? Para Kovács (1992) a questão da morte é um problema muito importante para o psicólogo, pois sua presença é requerida para trabalhar em hospitais, clínicas, com pacientes portadores de graves doenças e também com suicidas. É verdade que pouco ainda se tem escrito sobre tal questão, o que chega a parecer contraditório, levando em consideração que a morte é a preocupação universal do homem. Já que a Psicologia estuda a relação do ser humano com o mundo, a morte deveria ser assunto fundamental para a formação dos estudantes, tanto como campo de estudo, como também prática profissional.

Importante destacar que $43,5 \%$ dos entrevistados, disseram que sua prática profissional pode contribuir para pensamentos autodestrutivos. Ser Psicólogo e trabalhar mediando conflitos daqueles que vem ao nosso encontro é também um lugar de angústia e sofrimento. Assim como, reflete Kovács (1992, p.233): "Trabalhar com o sofrimento ou a perda de significado da existência do paciente, pode despertar no profissional as mesmas vivências, ferindo o seu narcisismo, e a sua onipotência, colocando-o diante do incompleto e do não-terminado."

E por fim, $71,20 \%$ se sentiram reflexivos ao responder o questionário. 0 ato de responder uma pesquisa com indagações referentes a temática da morte e suicídio propicia um momento de reflexão para os estudantes. Muitas vezes, por nossa imersão na cotidianidade, nos distanciamos da nossa condição de finitude. Sobre isso, Heidegger (1990) nos lembra:

[...] o fato de inicialmente e na maior parte das vezes, muitos não saberem da morte não pode ser aduzido como prova de que o ser-para-a-morte não pertence universalmente à presença. Esse fato apenas demonstra que, de início e na maior parte das vezes, a presença, em fugindo, encobre para si mesma o ser-para-a-morte mais próprio. (p. 33).

Cabe sempre a reflexão que enquanto aqui existirmos, estaremos sempre fadados ao fim, somos seres finitos. É então pela morte que a vida é ressignificada, é através da angústia do fim que podemos pensar a nossa existência. Pensar também o que nos embriaga de sentido, o que nos traz significado, o que nos move e quais as afetações que podem nos levar a certas escolhas, como antecipar de forma literal a vida, assim como acontece com aqueles que pensam e tentam suicídio. É importante também pensarmos que a morte é parte fundamental da vida enquanto processo, e como tal, deve estar presente nas discussões e formação de profissionais, em especial, da área de saúde mental.

\section{CONSIDERAÇÕES FINAIS}

Adentrar em uma temática tão complexa como é o suicídio, nos angustia, mas também nos move a buscar um olhar mais atento sobre o fenômeno. As ideações e tentativas de suicídio estão presentes ao nosso redor e são crescentes em todo mundo a cada ano, mesmo que silenciosamente e pouco notificadas. Algo que acontece a cada 40 segundos no mundo, como é o caso das tentativas 
de suicídio, nos convoca significativamente a falar e pensar tal temática, especialmente, para podermos construir políticas de enfrentamento a esta realidade. Muito embora tenhamos, hoje, a ampliação e gratuidade das ligações telefônicas ao Centro de Valorização da Vida - CVV e a campanha do "Setembro amarelo", visando a promover diálogos sobre o suicído em nossa sociedade. Entendemos que se faz necessário pensar a prevenção do suicídio como uma construção de um cuidado continuado, presente em ações que podem ser promovidas por universidades e demais dispositivos de saúde, contribuindo para promover a saúde mental de estudantes universitários e de toda população.

É importante perceber e lembrar que pesquisas como esta, nos aproximam deste fenômeno enquanto realidade presente, seja nas ideações ou até mesmo das tentativas de suicídio, mas fundamentalmente, nos mostram o quão mobilizador é falar e pensar sobre este assunto. Especialmente para estudantes de psicologia, futuros profissionais que serão convocados a manejar casos de ideação e tentativa de suicídio. Este estudo, desvela o sofrimento presente na formação do psicólogo, seja pela natureza da sua formação, ou pela intensidade que significa pensar, lidar com questões relativas ao humano, tal qual o é o suicídio. Percebemos ao longo da pesquisa, inclusive, que esta é uma realidade presente na narrativa de muitos deles, ao referirem terem eles mesmos, já ideado atentar contra a própria vida.

Esta pesquisa ressalta de fato que o sofrimento é algo inerente à existência humana, tal qual pensava Eça de Queiroz, ao afirmar que "a todo um viver corresponde um sofrer" (2012, p.87). Desta forma, os estudantes expressaram seus sofrimentos e essa dor também tem morada dentro da universidade. Desvelar e compreender as dificuldades dos estudantes e entender os fatores que podem propiciar a escolha por tirar a própria vida e não mais existir, como também os aspectos sociais e culturais para além da singularidade dos alunos, são fundamentais para pensarmos o suicídio, como uma escolha para enfrentar o sofrimento, anteriormente referenciado aqui por alguns de nossos entrevistados.

Percebemos e entendemos aqui, a necessidade de um espaço de acolhimento para os estudantes, que vise um cuidado psicológico e escuta deste sofrimento. Como também desenvolver ações e intervenções que possibilitem junto aos alunos a compreensão do suicídio, pois quando se conhece o fenômeno é possível uma prevenção mais efetiva. É importante também promover discussões coletivas a fim de favorecer uma reflexão mais ampla sobre a saúde mental dos estudantes de Psicologia e demais cursos, pensando inclusive a estrutura curricular, os espaços de socialização e lazer e a relação aluno-universidade. E ainda pensar e desenvolver, para além disso, outros estudos na mesma linha, adentrando as diversas áreas e campos de conhecimento.

\section{REFERÊNCIAS BIBLIOGRÁFICAS}


Alves, T. (2014). Depressão e ansiedade entre estudantes da área de saúde. Rev Med, 93(3), 101105. doi: https://doi.org/10.11606/issn.1679-9836.v93i3p101-105

Azevedo, A. K. S. \& Dutra, E. (2012). Relação Amorosa e Tentativa de Suicídio na Adolescência: uma Questão de (Des)Amor. Revista Da Abordagem Gestáltica, XVIII(1), 20-29.

Botega, N. (2014). Comportamento suicida: epidemiologia. Psicologia USP, 25(3), 231 - 236.

Calais, S. L., Andrade, L. M. B., \& Lipp, M. E. N. (2003). Diferenças de sexo e escolaridade na manifestação de Stress em adultos jovens. Psicologia: Reflexão e Crítica, 16(2), 257-263.

Cassorla, R. (1991). Do Suicídio: Estudos Brasileiros. São Paulo: Papirus.

Cassorla, R. (1998). O Suicídio. Cad. Saúde Pública, 14(1), 7-34.

Cassorla, R. (2004). Suicídio e autodestruição humana. In B. S. G. Werlang, \& J. N. Botega (Org.). Comportamento suicida (pp. 21-35). Porto Alegre: Artmed.

Cattapan P. (2012). Moralização do suicídio? Revista Iluminart, Ano IV(9), 182-194.

Conselho Nacional de Saúde. (2018). Resolução № 597, de 13 de Setembro de 2018. Brasília. Recuperado de: http://conselho.saude.gov.br/resolucoes/reso 18.htm

Dimenstein, M., Santos, Y., Brito, M., Severo, A., \& Morais, C. (2005). Demanda em saúde mental em unidades de saúde da família. Mental, 3(5), 33-42.

Dutra, E. (2000). Compreensão de tentativas de suicídio de jovens sob o enfoque da abordagem centrada na pessoa (Doutor). Instituto de Psicologia da Universidade de São Paulo.

Dutra, E. (2011). Pensando o suicídio sob a ótica fenomenológica hermenêutica: algumas considerações. Revista da Abordagem Gestáltica, XVII(2), 152-157.

Dutra, E. (2012). Suicídio de universitários: o vazio existencial de jovens na contemporaneidade. Estudos e Pesquisas em Psicologia, 12(3), 924-937.

Heidegger, M. (1990). Ser e Tempo. Partes I e II. Petrópolis: Vozes.

Junqueira, M. \& Kovács, M. (2008). Alunos de Psicologia e a Educação para a Morte. Psicologia Ciência e Profissão, 28(3), 506-519.

Kovács, M. (1992). Profissionais de Saúde diante da Morte. In M. Kovács, Morte e Desenvolvimento Humano (1a ed.). São Paulo: Casa do Psicólogo.

Kovács, M. (2013). Revisão crítica sobre conflitos éticos envolvidos na situação de suicídio. Revista Psicologia: Teoria E Prática, 15(3), 69 - 82.

Lovisi, G., Santos, S., Legay, L., Abelha, L., \& Valencia, E. (2009). Análise epidemiológica do suicídio no Brasil entre 1980 e 2006. Revista Brasileira de Psiquiatria, 31(Supl II), 86 - 93. 
Morais, S. \& Sousa, G. (2011). Representações sociais do suicídio pela comunidade de dormentes PE. Psicologia: Ciência e Profissão, 31(1), 160-175.

Ministério da Saúde (2009). Prevenção do Suicídio: Manual dirigido aos profissionais da Saúde aa Atenção Básica. São Paulo: Universidade Estadual de Campinas.

Organização Mundial da Saúde, (2006). Prevenção do suicídio: um recurso para conselheiros. Genebra.

http://www.who.int/mental_health/media/counsellors_portuguese.pdf>.

Queiroz, E. (2012). A cidade e as Serras. São Paulo: Melhoramentos.

Rocha, M., Boris, G., \& Moreira, V. (2012). A Experiência Suicida numa Perspectiva HumanistaFenomenológica. Revista Da Abordagem Gestáltica, XVIII(1), 69 - 78.

Roehe, M.V. (2006). Uma abordagem fenomenológica-existencial para a questão do conhecimento em psicologia. Estudos de Psicologia, 11(2), 153-158.

Sabino, F. (1986). Suíte ovalliana. In As melhores crônicas de Fernando Sabino. Rio de Janeiro: Record.

Silva, V. F., Oliveira, H. B., Botega, N. J., Marin-Leon, L., Barros, M. B. A., \& Dalgalarrondo, P. (2006). Fatores associados à ideação suicida na comunidade: um estudo de caso controle. Caderno de Saúde Pública, 22(9), 1835-1843.

Vieira, K., \& Coutinho, M. (2008). Representações Sociais da Depressão e do Suicídio elaboradas por estudantes de psicologia. Psicologia Ciência e Profissão, 28(4), 714-727. 